\title{
On Laminar Rich Premixed Polydisperse Spray Flame Propagation with Heat Loss
}

\author{
G. Kats and J. B. Greenberg \\ Faculty of Aerospace Engineering, Technion-Israel Institute of Technology, 32000 Haifa, Israel \\ Correspondence should be addressed to J. B. Greenberg; aer9801@technion.ac.il
}

Received 22 November 2015; Revised 4 February 2016; Accepted 7 February 2016

Academic Editor: Ashwani K. Gupta

Copyright ( 2016 G. Kats and J. B. Greenberg. This is an open access article distributed under the Creative Commons Attribution License, which permits unrestricted use, distribution, and reproduction in any medium, provided the original work is properly cited.

A mathematical analysis of laminar premixed spray flame propagation with heat loss is presented. The analysis makes use of a distributed approximation of the Arrhenius exponential term in the reaction rate expression and leads to an implicit expression for the laminar burning velocity dependent on the spray-related parameters for the fuel, gas-related parameters and the intensity of the heat losses. It is shown that the initial droplet load, the value of the evaporation coefficient, and the initial size distribution are the spray-related parameters which exert an influence on the onset of extinction. The combination of these parameters governs the manner in which the spray heat loss is distributed spatially and it is this feature that is the main factor, when taken together with volumetric heat loss, which determines the spray's impact on flame propagation and extinction.

\section{Introduction}

Spalding [1] was the first to treat the problem of a laminar gas flame propagating through a combustible premixture in the presence of heat losses, for example, due to heat loss by conduction to the walls of the combustion chamber or radiation. In keeping with experimental evidence it was found that for a given heat loss there exist two possible burning velocities, one stable and the other not. Extinction occurs at the point of traversal from the stable to the unstable mode of propagation. Essentially, this happens when the heat loss is too great. The theory agreed well with experiments for flame propagation and extinction in tubes. Subsequent work $[2,3]$ also dealt with similar problems of one-dimensional flame propagation and examined different aspects of extinction of these flames. Buckmaster [4] reexamined the aforementioned problem using asymptotic tools and was able to construct the slow and fast waves as well as to predict a simple explicit quenching criterion. Joulin and Clavin [5] considered the stability of laminar premixed flames subject to linear heat loss and found a variety of instabilities for the different regimes (slow and fast waves) examined by previous researchers. Nicoli and Clavin [6] considered the effect of variable heat loss intensities on the dynamics of a premixed flame. Clavin and Nicoli [7] investigated heat loss effects on stability limits of downward propagating premixed flames.

In the context of mathematical analysis of onedimensional premixed spray flames, some attention was directed to the influence of heat losses [8,9], although when the stability of such flames was considered heat losses were not accounted for [10-13]. However, in [8,9] the linear volumetric heat losses were taken as being of order $\varepsilon$, where $\varepsilon$ is inversely proportional to the activation energy of the assumed global chemical reaction, and were only applied in the region between the onset of droplet evaporation and the flame front. In addition, the sprays were taken to be monodisperse.

As pointed out by Sirignano [14] radiation impacts on individual droplet heating and evaporation in several ways. Primarily, droplets may be heated by radiation from high temperature gases. Or, alternatively, radiation may decrease the flame temperature so that radiative (and conductive) heat transfer to droplets will be diminished. In modeling the behavior of single droplets the radiative heating effect is expressed via a modification to the latent heat of evaporation. However, Sazhin [15], in discussing single droplets, argues 


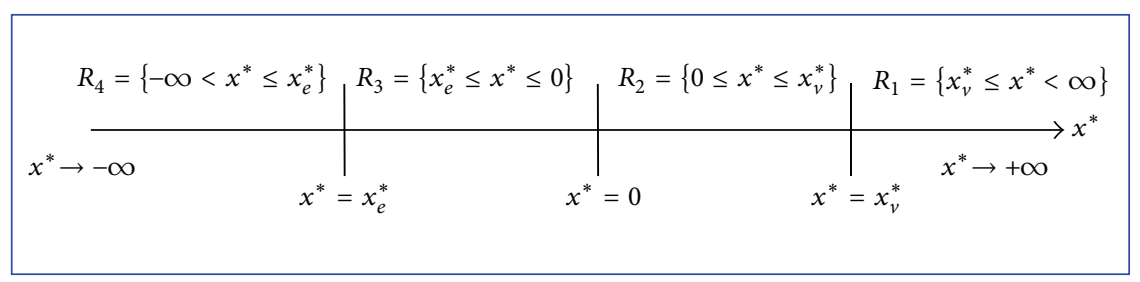

FIGURE 1: Schematic of the subregions considered for the analysis of a one-dimensional planar premixed spray flame in the presence of volumetric/radiative heat losses.

that taking them as grey opaque bodies "overlooks the fact that droplet radiative heating takes place not at their surface (as in the case of convective heating) but via the absorption of thermal radiation penetrating inside the droplets." $\mathrm{He}$ therefore assumes for modelling purposes that the droplet is semitransparent.

In the current paper we investigate the propagation of an off-stoichiometric rich laminar premixed polydisperse spray flame in the presence of heat loss, for the first time. In this paper we restrict our attention exclusively to the stable branch of propagation down to conditions of extinction. Our ultimate aim is to explore spray flame ignition since during the first moments of application of the igniter the role of heat losses can be rather dominant. It is a well-established fact that modern combustors in aircraft need to satisfy a large number of requirements. Of particular interest is the fact that under extreme conditions they must reignite following flame extinction without any problems and without any external help. The possibility of extinction also exists in cold and wet conditions (e.g., in a hailstorm) as well as at high altitudes due to oxygen starvation. The presence of liquid fuel in the form of a multisized spray of droplets that must first produce a sufficient amount of fuel vapor for successful ignition increases the difficulties. The current work is a prelude to such an ignition study that will be reported in the future.

In a previous publication [16] we modified a nonasymptotic mathematical approach $[17,18]$ to analyzing gas flame propagation and successfully applied it to examine the propagation of liquid fuel spray flames and double spray flames (i.e., both fuel and oxidizer supplied as a spray of droplets). For propagation studies this approach seems to be a viable alternative to an asymptotic approach. Here we adopt the same methodology.

The structure of the paper is as follows. We present the governing equations and the assumptions upon which they are based. We then explain how they are solved and present their solution. Finally, we examine how the combination of volumetric and spray-related heat losses influences the propagation and extinction conditions of the spray flames.

\section{Governing Equations and Problem Definition}

2.1. Assumptions. We consider a laminar one-dimensional premixed flame propagating into an off-stoichiometric fresh homogeneous mixture of fuel vapor, liquid fuel droplets, oxygen, and an inert gas. A schematic of the situation considered is shown in Figure 1. The flame is taken to propagate from left to right. The droplets are viewed from a far-field vantage point; that is, their average velocity is equal to that of their host environment. For qualitative purposes this approach has been demonstrated to be quite valid [19]. The spray is taken to be polydisperse; that is, at any point in space and time there is a distinct size distribution of the spray's droplets. The temperature of the droplets is taken to be that of the surroundings; essentially the droplets heat-up time is small compared to the characteristic time associated with their motion. Droplet evaporation is assumed negligible until a prescribed reference temperature $T_{v}$ (such as the boiling temperature of the liquid fuel) is attained.

The stoichiometry of the gas mixture that the flame front meets is taken to be fuel rich, so that the limiting reactant consumed by chemical reaction is oxygen. It is assumed that the various transport coefficients, such as thermal conductivity, diffusion coefficient, specific heat at constant pressure, and latent heat of vaporization of the droplets, can be satisfactorily specified by representative constant values. An overall reaction of the form $v_{F}$ fuel $+v_{O}$ oxidant $\rightarrow$ products is taken to describe the chemistry.

As the velocity of propagation of the flame is much less than the velocity of sound, dynamic compressibility effects in the mixture can be neglected. Thus, the density becomes only a function of the temperature through the gas law.

The polydisperse spray is described using the sectional method [20] in which the droplet size-distribution is divided into sections (or bins) and conservation equations are derived for the liquid fuel in each section allowing for droplet evaporation from a given section, for example, $j$, and addition to that section as droplets evaporate in the next section up and become eligible for membership in $j$.

The spatial region from $x^{*} \rightarrow+\infty$ to $x^{*} \rightarrow-\infty$ can be divided into four distinct regions:

(a) A prevaporization region where the system's temperature has not yet reached the critical temperature of the fuel at which significant evaporation begins to occur. This region is denoted by $R_{1}=\left\{x_{v}^{*} \leq x^{*}<\infty\right\}$.

(b) A preflame region in which chemical reaction has not yet begun because the temperature is less than the temperature required to initiate it. This is region $R_{2}=\left\{0 \leq x^{*} \leq x_{v}^{*}\right\}$.

(c) The flame region where reaction occurs, denoted by $R_{3}=\left\{x_{e}^{*} \leq x^{*} \leq 0\right\}$. 
(d) A postflame region where the reaction has essentially ceased because, due to heat loss, the temperature drops below the temperature that sustains the flame, $R_{4}=\left\{-\infty<x^{*} \leq x_{e}^{*}\right\}$.

Note that Figure 1 is simply a schematic drawing of the four aforementioned regions and does not reflect their actual scales which will be determined by the spray and gas environment parameters.

2.2. Governing Equations. In the presence of linear heat loss the governing conservation equations can be shown to be

$$
\begin{aligned}
\rho c_{p} \frac{\partial T}{\partial t^{*}}= & \lambda \frac{\partial^{2} T}{\partial x^{* 2}}+\rho q Y_{O} A \exp \left(-\frac{E}{R T}\right)-\widehat{\alpha}\left(T-T_{0}\right) \\
& -L S_{v}, \\
\rho \frac{\partial Y_{O}}{\partial t^{*}}= & \rho D_{O} \frac{\partial^{2} Y_{O}}{\partial x^{* 2}}-\rho Y_{O} A \exp \left(-\frac{E}{R T}\right), \\
\rho \frac{\partial Y_{d, j}}{\partial t^{*}}= & -S_{v, j}, \quad j=1,2,3, \ldots, N_{S},
\end{aligned}
$$

where

$$
S_{v j}=\Delta_{j} Y_{d, j}-\Psi_{j} Y_{d, j+1}
$$

is the source term for production of liquid fuel in droplets of section $j$, and the sectional vaporization coefficients are (see [20])

$$
\begin{array}{r}
\left(\Delta_{j}, \Psi_{j}\right)=1.5 \widehat{E}_{v}\left(\frac{3 d_{u j}-2 d_{l j}}{d_{u j}^{3}-d_{l j}^{3}}, \frac{d_{l j+1}}{d_{u j+1}^{3}-d_{l j+1}^{3}}\right) \\
j=1,2, \ldots, N_{S}, \Psi_{N_{S}}=0
\end{array}
$$

where $\widehat{E}_{v}$ is the liquid fuel's evaporation coefficient and $d_{l j}$ and $d_{u j}$ are the lower and upper diameters, respectively, defining droplet size section $j$.

$$
S_{v}=\sum_{j=1}^{N_{S}} S_{v j}
$$

$S_{v}$ is the source term for the production of fuel vapor by evaporating droplets in all sections. The sectional Damkohler numbers are based on $d^{2}$ law, which was confirmed by previous studies [21] to predict the actual vaporization history of an interacting droplet, especially in the initial period of combustion.

Note that the terms resulting from the chemical reaction are linear in the deficient reactant, which, for the rich offstoichiometric case herein discussed, is oxidant. (The nearstoichiometric case, in which the product of the oxidant and fuel vapor concentrations is present, is not considered here since the approach to be adopted was reported [18] as yielding considerably less satisfactory results under such circumstances.)

The boundary conditions for this set of equations are

$$
\begin{aligned}
& x^{*} \longrightarrow \infty: \quad Y_{O}=m_{\mathrm{Ou}}, T=T_{0}, Y_{d, j}=\delta_{j}, \\
& x^{*} \longrightarrow-\infty: \quad Y_{O}=0, T=T_{0}, Y_{d}=0 .
\end{aligned}
$$

2.3. Solution Approach. Following [18, 22] the nonlinear nature of the chemical source terms can be alleviated by replacing the exponential temperature-dependent term $A \exp (-E / R T)$ by the step function $k\left(T_{m}\right) H\left(T-T_{*}\right)$ in which

$$
k\left(T_{m}\right)=A \exp \left(-\frac{E}{R T_{m}}\right) .
$$

$T_{*}$ is found so that there is equality of the integrals with respect to $T$ of both the Arrhenius exponential and the step function over the entire range of temperatures (from the cold mixture temperature, $T_{0}$, to the highest temperature attained in the system, $T_{m}$ ):

$$
\int_{T_{0}}^{T_{m}} k\left(T_{m}\right) H\left(T-T_{*}\right) d T=\int_{T_{0}}^{T_{m}} A \exp \left(\frac{-E}{R T}\right) d T .
$$

It is not hard to show that this yields

$$
\begin{gathered}
\int_{T_{0}}^{T_{m}} k\left(T_{m}\right) H\left(T-T_{*}\right) d T=k\left(T_{m}\right)\left(T_{m}-T_{*}\right) ; \\
\int_{T_{0}}^{T_{m}} A \exp \left(\frac{-E}{R T}\right) d T \approx \frac{R T_{m}^{2}}{E} k\left(T_{m}\right)
\end{gathered}
$$

and we obtain

$$
T_{*}=T_{m}(1-\varepsilon), \quad \varepsilon=\frac{R T_{m}}{E} \ll 1
$$

so that in (1) and (2) use is made of

$$
\begin{aligned}
\widehat{K}_{O}(T) & =A \exp \left(-\frac{E}{R T_{m}}\right) H\left(T-T_{*}\right) \\
& =k\left(T_{m}\right) H\left(T-T_{*}\right) .
\end{aligned}
$$

For a spray flame the heat loss due to droplet evaporation also plays a role in the heat balance and it is therefore introduced via $T_{m}$, the maximum temperature attained in the system. In this way the step function specifically reflects the maximum value of the Arrhenius exponential function thereby capturing the essence of the physical meaning of that function.

The above governing equations (with their appropriate boundary conditions) describe the spray flame propagation from the perspective of laboratory coordinates. However, in order to extract a solution it proves more straightforward to rewrite the equations in coordinates attached to the flame front. Assuming the flame is moving at a constant speed $u$ in the positive $x$-direction (i.e., propagation from left to right) we can define the new coordinate $\xi=x^{*}-u \cdot t^{*}$, whereby the governing set of equations reduces to the following ordinary differential equations:

$$
\begin{aligned}
& D_{T} \frac{\partial^{2} T}{\partial \xi^{2}}+u \frac{\partial T}{\partial \xi}+\frac{q}{C_{p}} Y_{O} \widehat{K}_{O}(T)-\frac{L}{C_{p}} S_{v} \widehat{K}_{d}(T) \\
& \quad-\alpha\left(T-T_{0}\right)=0, \\
& D_{O} \frac{\partial^{2} Y_{O}}{\partial \xi^{2}}+u \frac{\partial Y_{O}}{\partial \xi}-Y_{O} \widehat{K}_{O}(T)=0, \\
& u \frac{\partial Y_{d, j}}{\partial \xi}-S_{v j} \widehat{K}_{d}(T)=0, \quad j=1,2,3, \ldots, N_{S},
\end{aligned}
$$


where

$$
\widehat{K}_{d}(T)=H\left(T-T_{v}\right)
$$

with $H$ being the Heaviside function used to ensure that droplet evaporation only occurs significantly once the temperature of the fuel droplets reaches the fuel's boiling point, $D_{T}=\lambda / \rho c_{p}$ is the thermal diffusion coefficient, and $\alpha=\widehat{\alpha} / \rho c_{p}$ is the heat loss coefficient. Henceforth, for convenience, we assume a unity Lewis number $\left(D_{T}=D_{O}\right)$.

Note that the chemical source terms in (13) and (14) are applicable only for $T \geq T_{*}$ but due to our coordinate transformation we can replace $H\left(T-T_{*}\right)$ by $H(-\xi)$ as the system is invariant under spatial translation and we can take the location of the interface between the second and third regions as $=0$.

Accordingly, the boundary and matching conditions that are applicable are

$$
\begin{array}{ll}
\xi=\xi_{v}: & {\left[Y_{O}\right]=\left[Y_{O}^{\prime}\right]=0,\left[Y_{d, j}\right]=0, T=T_{v},[T]=\left[T^{\prime}\right]=0,} \\
\xi=0: & {\left[Y_{O}\right]=\left[Y_{O}^{\prime}\right]=0,\left[Y_{d, j}\right]=0, T=T_{*},[T]=\left[T^{\prime}\right]=0,} \\
\xi=\xi_{e}: & {\left[Y_{O}\right]=\left[Y_{O}^{\prime}\right]=0,\left[Y_{d, j}\right]=0, T=T_{*},[T]=\left[T^{\prime}\right]=0,} \\
\xi=\xi_{m}: & {\left[Y_{O}\right]=\left[Y_{O}^{\prime}\right]=0,\left[Y_{d, j}\right]=0, T=T_{m},[T]=\left[T^{\prime}\right]=0, T^{\prime}\left(\xi_{m}\right)=0,}
\end{array}
$$

where derivatives with respect to $\xi$ are denoted by / and $\xi_{v}, \xi_{e}$, and $\xi_{m}$ are, respectively, the interface locations where finiterate vaporization begins and the interface between the region where the chemical reaction takes place and the region where it ceases and a spatial point where the maximum temperature $T_{m}$ is attained.

Physically, $\xi_{m}$ must be located in the middle of the third region $\xi_{e}<\xi_{m}<0$, where the reaction is adding heat to the system but the volumetric/radiative heat loss is of considerable competitive importance.

\section{Solution}

The solution of the governing equations is found in every region separately with the matching conditions connecting the solutions. We present the results for the four relevant regions:

$$
\begin{gathered}
\text { In } R_{1}=\left\{\xi_{v} \leq \xi<\infty\right\} \\
T(\xi)=T_{0}+\left(T_{v}-T_{0}\right) \exp \left[\lambda_{2}\left(\xi-\xi_{v}\right)\right], \\
Y_{O}(\xi)=m_{O u}\left(1+\frac{\mu_{1}}{\mu_{2}} \exp \left(-\frac{u}{D_{O}} \xi\right)\right), \\
Y_{d, j}=\delta_{j}, \quad j=1,2,3, \ldots, N_{S} . \\
\text { In } R_{2}=\left\{0 \leq \xi \leq \xi_{v}\right\} \\
T(\xi)=T_{0}+\omega_{1} \exp \left[\lambda_{1}\left(\xi-\xi_{v}\right)\right] \\
+\omega_{2} \exp \left[\lambda_{2}\left(\xi-\xi_{v}\right)\right]+\frac{L}{C_{p}} P\left(S_{v}(\xi)\right),
\end{gathered}
$$

$$
\begin{aligned}
& Y_{O}(\xi)=m_{\mathrm{O} u}\left(1+\frac{\mu_{1}}{\mu_{2}} \exp \left(-\frac{u}{D_{O}} \xi\right)\right), \\
& Y_{d, j}(\xi)=\sum_{i=j}^{N_{S}} \Omega_{j i} \exp \left[\frac{\Delta_{i}}{u}\left(\xi-\xi_{v}\right)\right], \\
& j=1,2,3, \ldots, N_{S} \text {. } \\
& \text { In } R_{3}=\left\{\xi_{e} \leq \xi \leq 0\right\} \\
& T(\xi)=T_{0}+\omega_{1} \exp \left[\lambda_{1}\left(\xi-\xi_{v}\right)\right]-\Gamma m_{\mathrm{Ou}}\left(\frac{\mu_{1}}{\mu_{2}}+1\right) \\
& \cdot\left[\frac{\lambda_{2}-\mu_{1}}{\lambda_{1}-\lambda_{2}} \exp \left(\lambda_{1} \xi\right)+\exp \left(\mu_{1} \xi\right)\right]+\frac{L}{C_{p}} \\
& \text {-P }\left(S_{v}(\xi)\right) \text {, } \\
& Y_{O}(\xi)=m_{\mathrm{Ou}}\left(1+\frac{\mu_{1}}{\mu_{2}}\right) \exp \left(\mu_{1} \xi\right), \\
& Y_{d, j}(\xi)=\sum_{i=j}^{N_{S}} \Omega_{j i} \exp \left[\frac{\Delta_{i}}{u}\left(\xi-\xi_{v}\right)\right], \\
& j=1,2,3, \ldots, N_{S} \text {. } \\
& \text { In } R_{4}=\left\{-\infty<\xi \leq \xi_{e}\right\} \\
& =T_{0} \\
& +\left\{T_{*}-T_{0}-\frac{L}{C_{p}} P\left(S_{v}\left(\xi_{e}\right)\right)\right\} \exp \left[\lambda_{1}\left(\xi-\xi_{e}\right)\right] \\
& +\frac{L}{C_{p}} P\left(S_{v}(\xi)\right)
\end{aligned}
$$




$$
\begin{aligned}
& Y_{O}(\xi)=, \\
& Y_{d, j}(\xi)=\sum_{i=j}^{N_{S}} \Omega_{j i} \exp \left[\frac{\Delta_{i}}{u}\left(\xi-\xi_{v}\right)\right], \\
& j=1,2,3, \ldots, N_{S},
\end{aligned}
$$

where

$$
\begin{aligned}
& P\left(S_{v}(\xi)\right)=\sum_{j=1}^{N_{S}}\left\{\Delta_{j} \sum_{i=j}^{N_{S}} \frac{\Omega_{j i} \exp \left[\left(\Delta_{i} / u\right)\left(\xi-\xi_{v}\right)\right]}{D\left(\Delta_{i} / u\right)^{2}+u\left(\Delta_{i} / u\right)-\alpha}\right. \\
& \left.-\Psi_{j} \sum_{i=j+1}^{N_{S}} \frac{\Omega_{j+1, i} \exp \left[\left(\Delta_{i} / u\right)\left(\xi-\xi_{v}\right)\right]}{D\left(\Delta_{i} / u\right)^{2}+u\left(\Delta_{i} / u\right)-\alpha}\right\} \text {, } \\
& P^{\prime}\left(S_{v}(\xi)\right) \\
& =\sum_{j=1}^{N_{S}}\left\{\Delta_{j} \sum_{i=j}^{N_{S}} \frac{\Omega_{j i}\left(\Delta_{i} / u\right) \exp \left[\left(\Delta_{i} / u\right)\left(\xi-\xi_{v}\right)\right]}{D\left(\Delta_{i} / u\right)^{2}+u\left(\Delta_{i} / u\right)-\alpha}\right. \\
& \left.-\Psi_{j} \sum_{i=j+1}^{N_{S}} \frac{\Omega_{j+1, i}\left(\Delta_{i} / u\right) \exp \left[\left(\Delta_{i} / u\right)\left(\xi-\xi_{v}\right)\right]}{D\left(\Delta_{i} / u\right)^{2}+u\left(\Delta_{i} / u\right)-\alpha}\right\}, \\
& \Omega_{j i}=\frac{\Omega_{j+1, i} \Psi_{j}}{\Delta_{j}-\Delta_{i}}, \quad i \neq j, \\
& \Omega_{j i}=\delta_{j}-\sum_{i=j+1}^{N_{S}} \Omega_{j i}, \quad i=j, \\
& \omega_{1}=-\frac{L}{C_{p}} \frac{P^{\prime}\left(S_{v}\left(\xi_{v}\right)\right)-\lambda_{2} P\left(S_{v}\left(\xi_{v}\right)\right)}{\lambda_{1}-\lambda_{2}}, \\
& \omega_{2}=T_{v}-T_{0}+\frac{L}{C_{p}} \frac{P^{\prime}\left(S_{v}\left(\xi_{v}\right)\right)-\lambda_{1} P\left(S_{v}\left(\xi_{v}\right)\right)}{\lambda_{1}-\lambda_{2}}, \\
& \Gamma=\frac{q k\left(T_{m}\right)}{C_{p}\left[k\left(T_{m}\right)-\alpha\right]}, \\
& \lambda_{1}=\frac{u}{2 D_{T}}\left(d_{T}-1\right), \quad(>0), \\
& \lambda_{2}=-\frac{u}{2 D_{T}}\left(d_{T}+1\right), \quad(<0), \\
& \phi=\frac{\alpha D_{T}}{u^{2}}, \\
& d_{T}=\sqrt{1+4 \phi}, \quad(>1), \\
& \mu_{1}=\frac{u}{2 D_{O}}\left(d_{O}-1\right), \quad(>0), \\
& \mu_{2}=-\frac{u}{2 D_{O}}\left(d_{O}+1\right), \quad(<0),
\end{aligned}
$$

$$
\begin{aligned}
& d_{O}=\sqrt{1+4 B}, \\
& B=\frac{k\left(T_{m}\right) D_{O}}{u^{2}} .
\end{aligned}
$$

An explicit formula for the burning velocity cannot be extracted; however, by applying matching and boundary conditions a set of coupled implicit algebraic equations are obtained through which $u, T_{m}, \xi_{m}, \xi_{e}, \xi_{v}$ can be found by using a numerical iterative method. The solution is based on the assumption that $\exp \left(\mu_{1} \xi_{e}\right) \rightarrow 0$ which can be readily verified.

In the limit of infinite vaporization coefficient $\left(\widehat{E}_{v} \rightarrow \infty\right)$ when the spray of liquid fuel droplets evaporates in a single vaporization front, some simplification of the afore-described solutions is achieved (see Appendix for details).

\section{Results and Discussion}

Use was made of the analytical solution in the previous section to examine the effect of heat loss and fuel spray parameters on conditions for spray flame propagation and extinction. The data used for the calculations was as follows (unless otherwise specified):

$$
\begin{aligned}
q & =1.279 \times 10^{7} \mathrm{~J} / \mathrm{kg}, \\
L & =0.04 \mathrm{Q}, \\
\lambda & =0.02512 \mathrm{Wm} / \mathrm{K}, \\
A & =10^{10} \mathrm{~s}^{-1}, \\
E & =2 \times 10^{8} \mathrm{~J} / \mathrm{kmol}, \\
c_{p} & =1255.92 \mathrm{~J} / \mathrm{kg} \mathrm{K}, \\
T_{0} & =300 \mathrm{~K}, \\
T_{v} & =400 \mathrm{~K}, \\
\widehat{E}_{v} & =1.4524 \cdot 10^{-15} \mathrm{~m}^{2} / \mathrm{s} .
\end{aligned}
$$

The chemical kinetic scheme employed concerns the burning of $\mathrm{n}$-decane and relevant thermochemical data was taken from $[23,24]$. By specifying the initial fraction of liquid fuel to the total fuel (vapor + liquid) in the fresh mixture, $\sum_{j=1}^{N_{S}} \delta_{j} /\left(m_{F u}+m_{d u}\right)=\delta$, it can be shown that the mass fractions in the fresh mixture are given by the following expressions:

$$
\begin{aligned}
& \left(m_{\mathrm{Ou}}, m_{d u}, m_{\mathrm{Fu}}\right) \\
& \quad=\left(s\left\{1-m_{d u}-m_{F u}\right\}, \frac{s \delta}{\left(1+\alpha_{\mathrm{OF}} / \varphi\right)}, m_{d u} \frac{(1-\delta)}{\delta}\right)
\end{aligned}
$$

unless $\delta=0$ for which

$$
m_{F u}=\frac{s}{\left(s+\alpha_{\mathrm{OF}} / \varphi\right)},
$$

where $s$ is the mole fraction of oxygen in the fresh mixture, $\alpha_{\mathrm{OF}}$ is the stoichiometric coefficient, and $\varphi$ is the equivalence ratio. Here $\varphi$ is taken as 2 and $\alpha_{O F}=3.5$. 


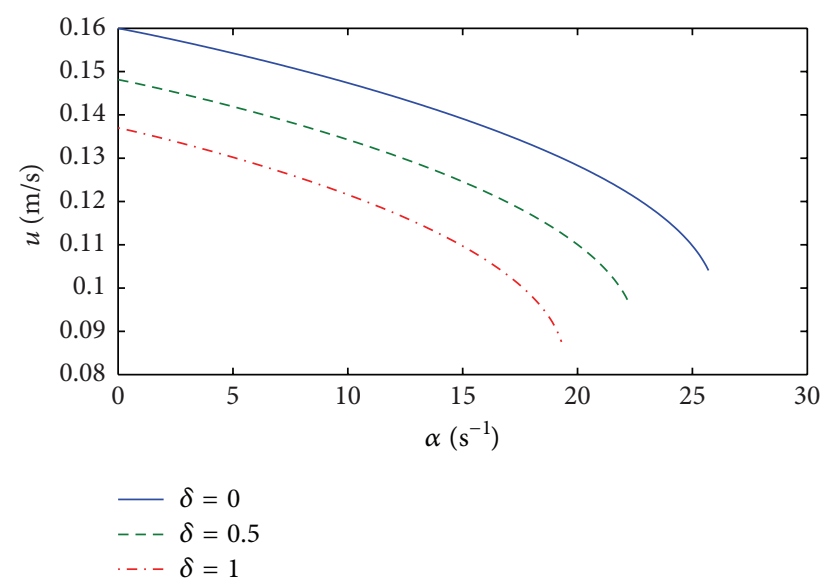

FIGURE 2: Influence of heat loss parameter on spray flame propagation velocity for different initial droplet loads-evaporation front case.

In order to extract and highlight the various factors at work in the fuel rich spray flames under consideration here we focus on three cases: (a) evaporation of the droplets in a single vaporization front (the solution for this case is given in Appendix), (b) finite rate evaporation but with all droplets subsumed into a single section (monosectional description of the spray with solution derivable by setting $N_{S}=1$ in the analysis of the previous section), and (c) the afore-detailed full polydisperse case. Case (a) is applicable when the liquid fuel is highly volatile. Case (b) applies to a less volatile fuel and is modeled to capture only the gross features of the spray impact on the combustion. Case (c) applies to a less volatile fuel but with the details of the spray size structure accounted for.

(a) Evaporation in a Front. We begin our discussion of the predictions of the theory by considering the case for which the liquid droplets evaporate in a sharp front. In Figure 2 a plot is presented of the spray flame's propagation velocity for different initial liquid fuel loads, $\delta$, as a function of the heat loss parameter, $\alpha$. For the purely gaseous case, $\delta=0$, the behavior of the velocity follows the classical behavior (see, e.g., [4]), with a decrease in the velocity resulting from increasing the heat loss. Of course, this is to be expected as a result of the competing exothermic-endothermic mechanisms at play. Eventually, flame extinction occurs at some critical value of $\alpha$. With the fuel supplied as a liquid spray only, that is, $\delta=1$, it is readily observed that the flame propagation velocity is less than that of its gaseous counterpart for any given value of $\alpha$. This is not surprising since, even without volumetric/radiative heat loss, the droplets themselves must absorb heat for evaporation, thereby automatically lowering the flame temperature and, hence, the flame velocity (see, also, $[10,16])$. As the droplet evaporation takes place in a front this source of heat loss is quite concentrated leading to a notable influence on the flame velocity. In addition, extinction of the spray flame occurs at a lower value of the heat loss parameter $\alpha$. This is understandable as both the distributed heat loss from the surroundings and

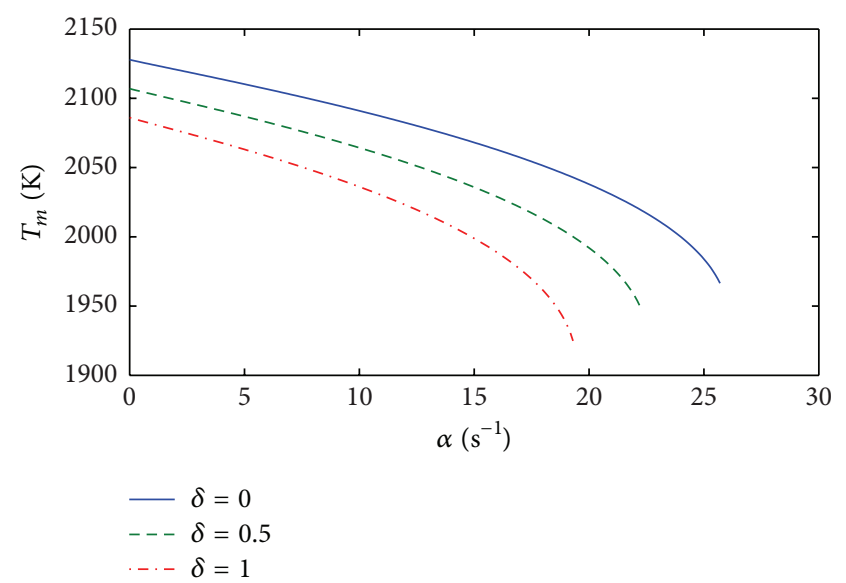

FIGURE 3: Influence of heat loss parameter on spray flame temperature for different initial droplet loads-evaporation front case.

the liquid droplets heat loss combine to overcome the exothermic chemical reaction.

The case in which $50 \%$ of fuel is supplied as liquid and $50 \%$ as vapor is also illustrated in Figure 2. It can be seen that, not surprisingly, the relevant curve lies in between the limiting curves which we have discussed.

In Figure 3 the flame temperature is drawn as a function of the heat loss parameter. The curves clearly reflect the discussion of Figure 2 and show the rather drastic effect of the heat loss particularly in the proximity of extinction conditions.

It is known from the theory of gas flame propagation [4] that the extinction velocity when linear heat loss is present is $e^{-1 / 2}$ times the adiabatic flame velocity. For spray flames the two sources of heat loss play a role, namely, radiative/volumetric heat loss and heat loss, due to absorption of heat by the liquid droplets for evaporation. In Figure 4 we examine the relative importance of these heat losses by plotting the log of the ratio of the flame velocity at extinction to the adiabatic gas flame velocity as a function of the initial liquid spray load, $\delta$. The green line with circles is the classical result when only radiative/volumetric heat loss is accounted for and it is readily seen to be constant at the value of $e^{-1 / 2}$. The blue continuous unmarked line shows the decrease in the spray flame burning velocity predicted when only droplet heat loss is accounted for. In this case the heat absorbed by the droplets for evaporation is not sufficient to extinguish the flame and the velocity ratio is always larger than $e^{-1 / 2}$. When both heat losses are included in the model the red line with boxes is obtained. (Note that since the flame velocity at extinction is used to construct this figure the value of the heat loss parameter, $\alpha$, varies along the curve (cf. Figure 2).) The ratio of velocities is now evidently dependent on the initial liquid droplet load, and a factor of about $e^{-0.66}$ is found when $\delta=1$.

In view of these findings and the underlying rationale it would seem that the latent heat of vaporization of the liquid fuel should be an important factor in determining spray flame velocity and extinction conditions. This influence is shown in 


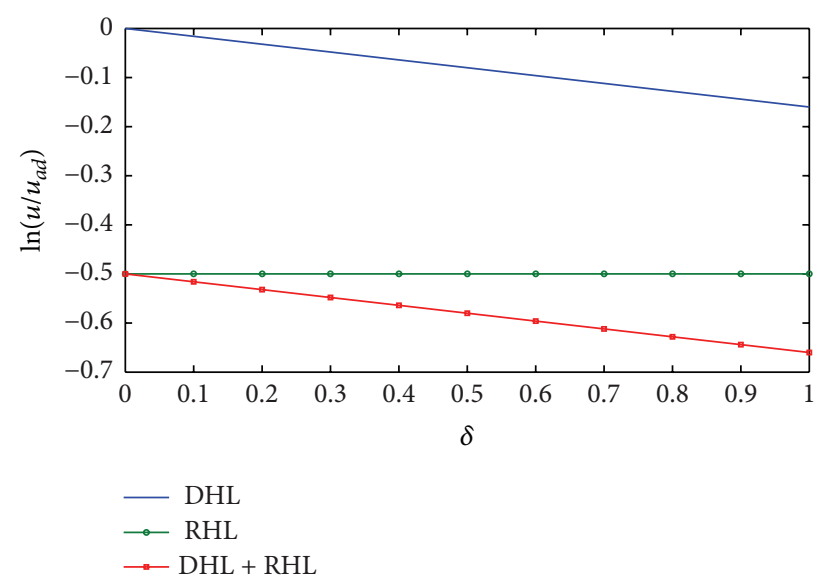

FIGURE 4: Relative importance of sources of heat loss in determining the flame velocity of laminar spray flames as function of the initial liquid fuel load, evaporation front case. $\mathrm{DHL}=$ droplet heat loss only, RHL $=$ radiative/volumetric heat loss only, and DHL + RHL $=$ combined droplet and radiative/volumetric heat loss.

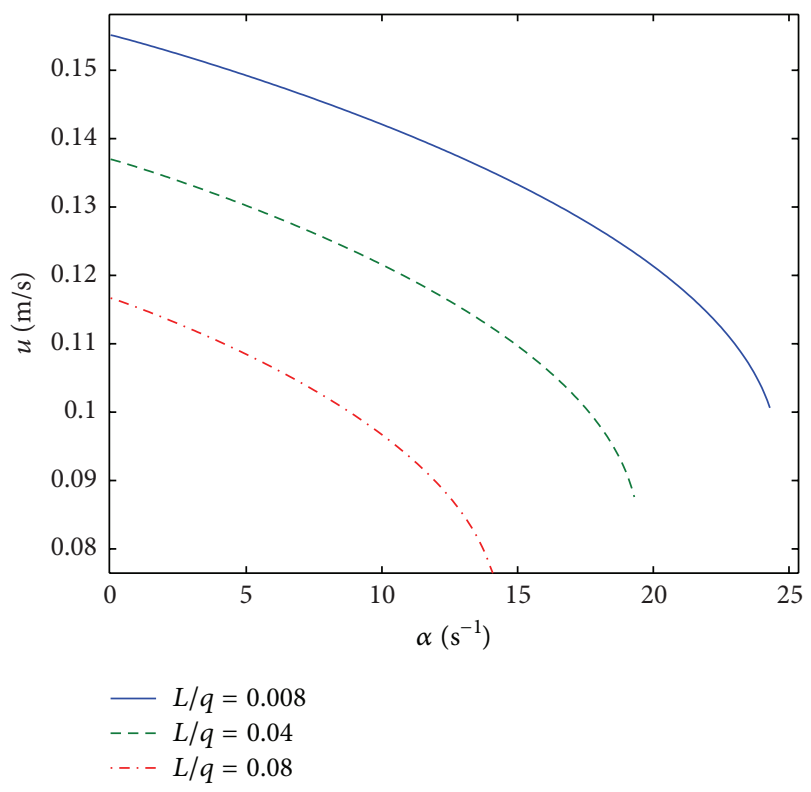

FIGURE 5: Influence of latent heat of vaporization on spray flame propagation velocity-evaporation front case.

Figure 5 in which the flame velocity is drawn as a function of the volumetric/radiative heat parameter for different values of the ratio of the latent heat to the heat of reaction. The effect is quite striking with the value of the flame velocity decreasing by a factor of $50 \%$ (for a fixed value of $\alpha$ ) as the latent heat increases by a factor of 10 . Moreover, the critical value of $\alpha$ for extinction decreases by a factor of $67 \%$ as the latent heat of vaporization increases tenfold.

(b) Monosectional Spray. The graphs presented so far related to the case in which the spray of fuel droplets evaporates in a sharp front. Attention will now be turned to the monosectional case with a finite evaporation rate. In Figure 6

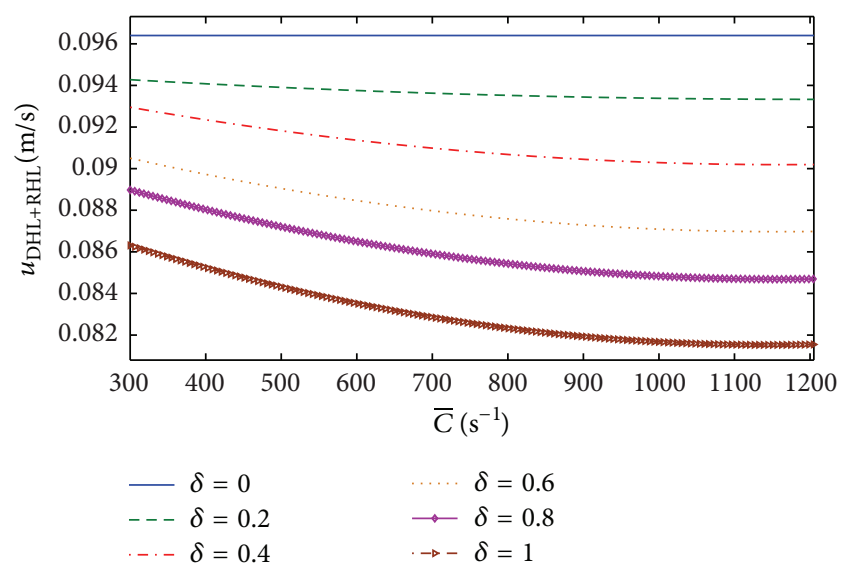

FIGURE 6: Influence of vaporization coefficient on spray flame propagation velocity at critical values of volumetric/radiative heat loss parameter for different initial droplet loads, monosectional spray.

the spray flame propagation velocity is drawn as a function of the evaporation coefficient, $\bar{C}=1.5 \widehat{E}_{v}\left(3 d_{u}-2 d_{l}\right) /\left(d_{u}^{3}-\right.$ $\left.d_{l}^{3}\right)$ (see (5)), at the values of the relevant critical volumetric/radiative heat loss parameter, and for different values of the initial fuel droplet load. For this case increasing the value of $\bar{C}$ is equivalent to using a more volatile fuel (i.e., increasing $\widehat{E}_{v}$ ) and/or using smaller droplets in the spray. For any given load it is clear that the velocity decreases as the evaporation coefficient increases. In fact as $\bar{C} \rightarrow \infty$ the velocity levels off at the value appropriate to the evaporation front case, as anticipated. In addition, as the initial droplet load increases the critical velocity decreases, irrespective of the value of the vaporization coefficient. This, too, is in keeping with the prediction of the evaporation front case (see, e.g., Figure 2).

In Figure 7 we examine the influence of the vaporization coefficient in determining the flame velocity as a function of the initial liquid fuel load by plotting the log of the ratio of the flame velocity at extinction to the adiabatic gas flame velocity as a function of the vaporization coefficient. It is clear that as $\bar{C}$ increases, for all values of $\delta$, the logarithm of the velocity ratio decreases below the value of -0.5 with the effect being greatest when the fuel is supplied in liquid form, that is, $\delta=1$. In addition, it can be observed that for large values of the evaporation coefficient the relevant curve overlaps with that of Figure 4 for the case of the evaporation front. Whereas the heat loss due to volumetric/radiative heat loss is distributed throughout the entire field, the more focused the heat loss due to droplet evaporation the greater the effect on critical conditions for extinction. Once again it is evident that the influence of the spray parameter, this time in the form of the evaporation coefficient, combines with that of the volumetric/radiative heat loss so that the classical $e^{-1 / 2}$-factor is modified. The maximum modification corresponds to the case of an infinitely large rate of evaporation.

(c) Polydisperse Spray. Having established the important characteristic features of a fuel spray and their role in flame 
TABLE 1: The sectional diameters $d_{j}(\mu \mathrm{m})$ and initial droplet size distributions.

\begin{tabular}{lcccccccccc}
\hline Section number & 1 & 2 & 3 & 4 & 5 & 6 & 7 & 8 \\
\hline Section diameters & $1-5$ & $5-10$ & $10-20$ & $20-30$ & $30-40$ & $40-50$ & $50-70$ & $70-90$ & $90-110$ \\
\hline Distribution 1 & 0 & 0 & 0 & 0 & 0 & 1 & 0 & 0 \\
\hline Distribution 2 & 0 & 0 & 0.207 & 0 & 0 & 0 & 0 & 0 \\
\hline Distribution 3 & 0.0005 & 0.0005 & 0.0141 & 0.0793 & 0.1662 & 0.2464 & 0.2349 & 0.1547 & 0.1034 \\
\hline
\end{tabular}

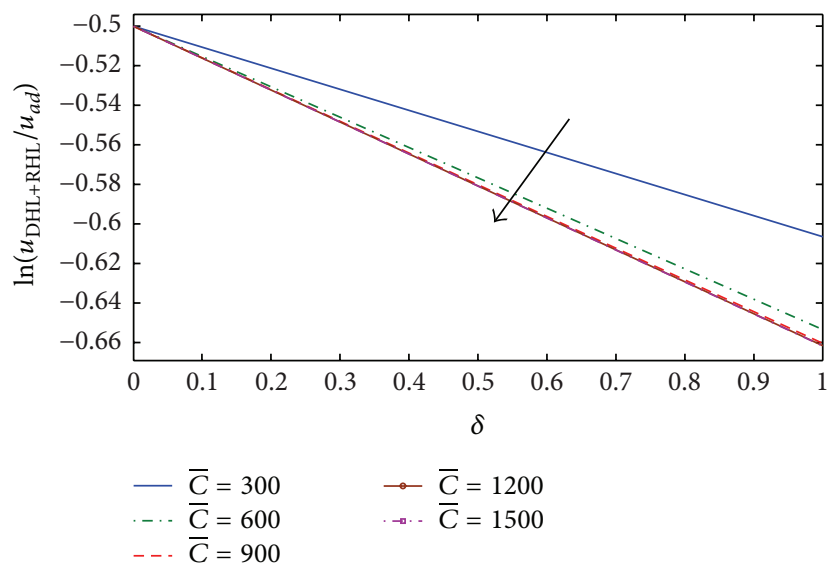

FIGURE 7: Influence of the vaporization coefficient in determining the flame velocity of laminar spray flames as function of the initial liquid fuel load, monosectional spray.

propagation in the presence of heat losses without recourse to the actual droplet sizes within the spray we turn our attention to the impact of the initial spray droplet size distribution. To this end we make use of three quite different initial spray distributions that are listed in Table 1, together with the definitions of the size sections utilized.

The numbers in each distribution's columns represent the fraction of liquid fuel (in the relevant size section) in the total liquid fuel supplied. Distribution 1 is initially monosectional but will become multisize once evaporation occurs and droplets become ineligible for membership in section 6 . Distribution 2 is bidisperse, initially having almost $80 \%$ liquid fuel in the highest section, number 9 , and the rest in much smaller droplets in section 3. Finally, the third distribution has droplets initially well spread out throughout all size sections and is probably closer to what exists in real life. These three different size distributions have a common Sauter Mean Diameter (SMD) of $44.8 \mu \mathrm{m}$. The SMD is the ratio of the volume of droplets in the spray to their surface area and is often used to characterize a polydisperse spray by an equivalent spray of single size droplets all of which have a diameter equal to the SMD. However, there is evidence that this characterization may sometimes be misleading [11, 25, 26].

In Figures 8, 9, and 10 the profiles of the sectional fuel mass fractions for the three initial size distributions are drawn, for comparison. $m_{d u}$ was taken as 0.1.

Recall that the flame is propagating from left to right with the close vicinity of the point $\xi=0$ marking the intense

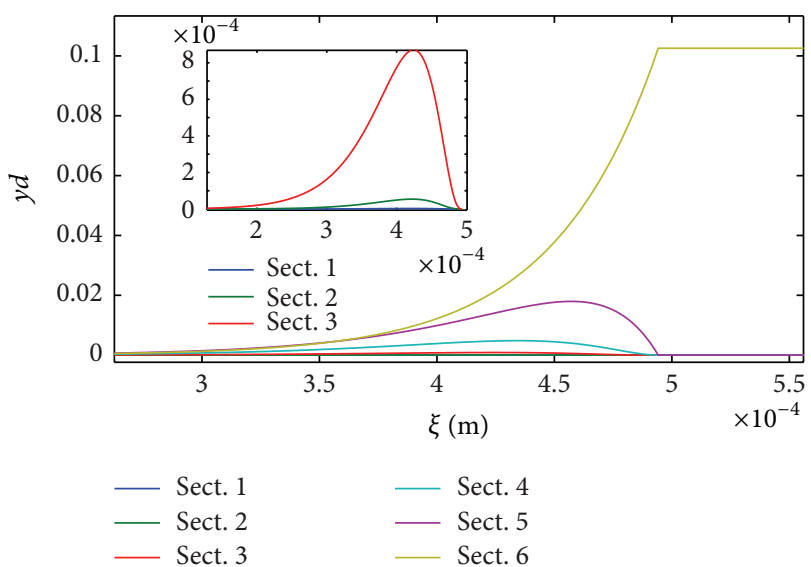

FIGURE 8: Liquid fuel sectional mass fractions profiles in onedimensional laminar spray flame propagation, initial size distribution 1 .

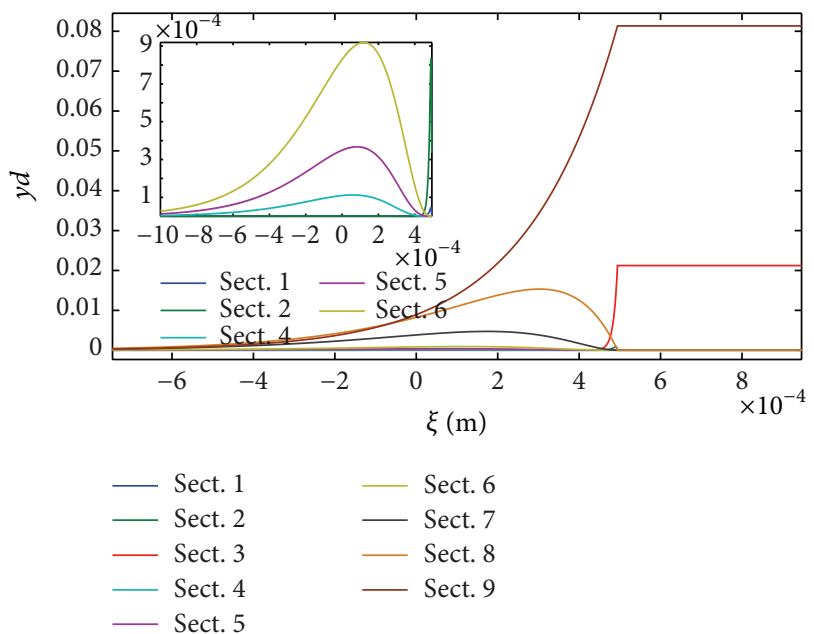

FIGURE 9: Liquid fuel sectional mass fractions profiles in onedimensional laminar spray flame propagation, initial size distribution 2 .

flame reaction zone. The redistribution of liquid droplets in all three cases as they evaporate and migrate down the size sections is apparent. For example, for distribution 1 all droplets initially occupy section 6 . As they evaporate there is a transfer to the initially unoccupied section 5 in which a build of liquid fuel is readily observable. Subsequently, the relocation to lower sections from section 5 occurs as droplets evaporate and become ineligible for membership in section 5. Similarly, behavior is found for the lower sections, too. 


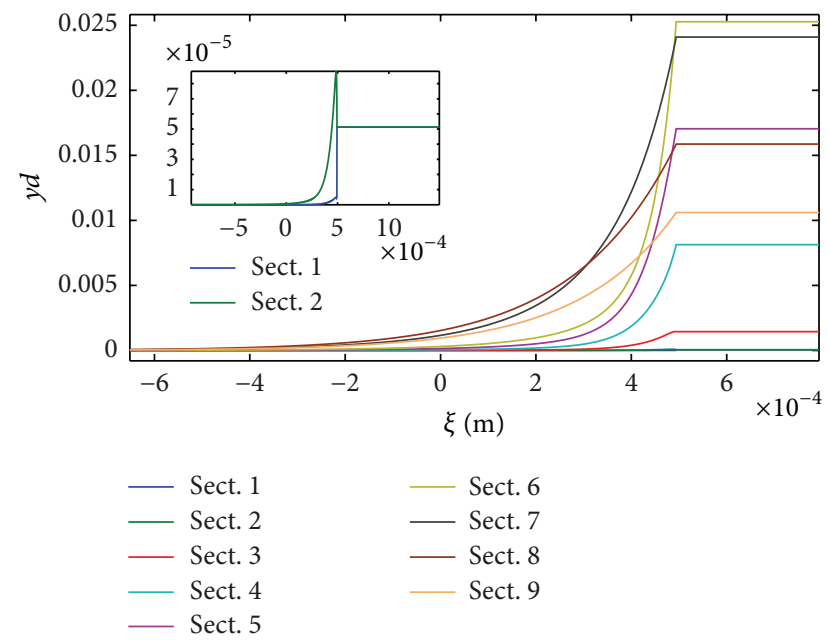

FIgURE 10: Liquid fuel sectional mass fractions profiles in onedimensional laminar spray flame propagation; initial size distribution 3.

However, what should also be noted, for the data utilized here, is the spatial distribution of the liquid fuel. For distribution 1 virtually all the liquid fuel evaporates before reaching the reaction zone, whereas for distributions 2 and 3 this is not the case. Although for these latter distributions much vapor is released upstream of the flame region noticeable continued evaporation occurs downstream of the flame front as the droplets pass through the flame into the hot products region. This will lead to different spatially distributed heat release behaviors depending on the internal spray structure (i.e., size distribution) and its evolution as the droplets absorb heat for evaporation.

Consider Figure 11 in which the velocity at extinction is drawn as a function of the initial liquid load for all three initial droplet size distributions. It is clear that for $\delta \neq 0$ the initial droplet distribution has a noticeable influence over the velocity at extinction. Distribution 1 leads to the lowest velocity; distribution 2 leads to the highest velocity with distribution 3 in between. At most the discrepancy is about $9 \%$ (comparing distributions 1 and 2) and about $2 \%$ (comparing distributions 1 and 3 ). This ordering is also reflected in Figure 12 in which the influence of the volumetric heat loss on the flame velocity is charted for three initial liquid fuel loads and for all three initial size distributions. The underlying rationale for this behavior can be deduced from Figure 13 where the flame temperatures associated with the velocities of Figure 11 are drawn. First we isolate the effect of the initial total liquid load. For any value of $\alpha$ for which a flame exists and for any initial droplet size distribution the flame temperature drops as $\delta$ increases. As we have seen before this is due to the increased heat loss sustained due to the droplets heat absorption for evaporation. This, in turn, influences the speed of propagation and lowers it accordingly.

Now isolate the effect of the droplet size distribution for a fixed value of $\delta$ and $\alpha$. It is clear that size distribution 1 leads to the lowest flame temperature followed by distribution 3 with the highest flame temperature supplied when distribution 2

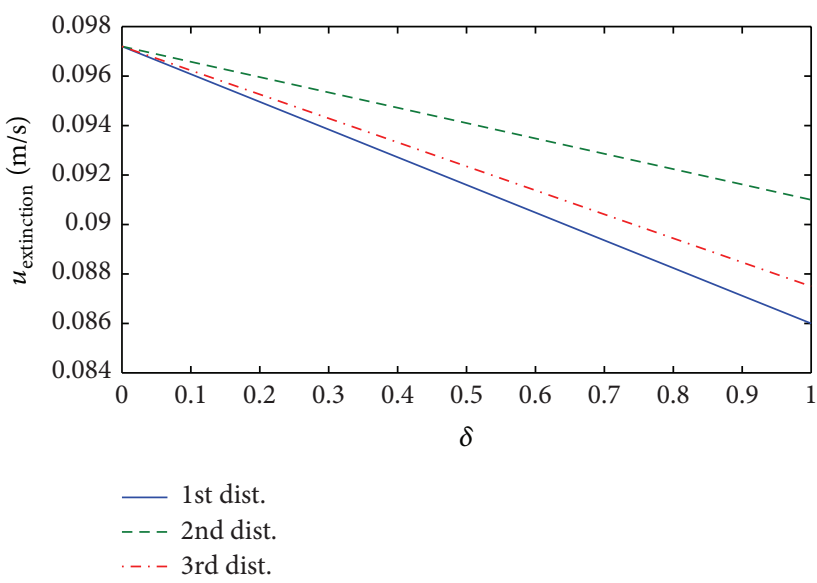

FIGURE 11: Flame velocity at extinction versus initial liquid droplet load-influence of initial droplet distribution.

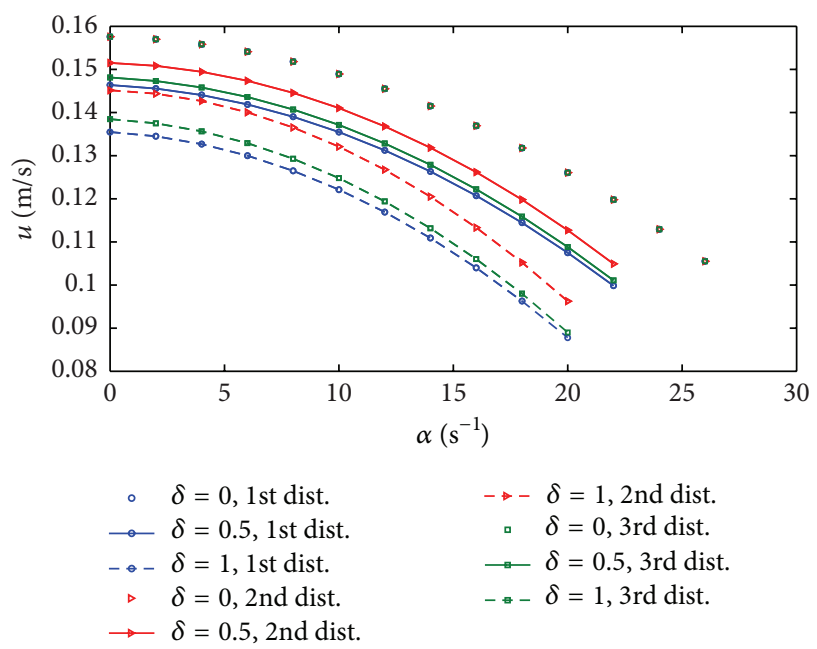

FIGURE 12: Influence of heat loss parameter on spray flame propagation velocity for different initial droplet loads-polydisperse case.

is used. Evidently, the initially monosectional distribution produces the most focused heat loss due to the initial concentration of droplets in section 6 . At the other extreme the least focused heat loss results from the bidisperse distribution 2. Although the smaller droplets in section 3 evaporate fairly rapidly thereby lowering the flame temperature somewhat, it is the large fraction of large droplets initially in section 9 which evaporate gradually that dominates the droplet heat loss mechanism thereby lessening the effect of heat loss when compared to that of distribution 1 . Distribution 3, which has droplets spread throughout the size range involved, yields a situation between that generated by the other two distributions, as can be readily observed in Figures 11 and 12. Thus, it is the way in which heat loss due to droplet evaporation is spatially distributed that determines the flame temperature and velocity. This sharpens our observations for the aforediscussed cases of the evaporation front and monosectional spray for which the details of the initial size distribution were dealt with in an integral fashion. 
TABLE 2: The sectional diameters $d_{j}(\mu \mathrm{m})$ and initial droplet size distributions for examining the influence of droplet size on spray flame propagation.

\begin{tabular}{lcccccccccc}
\hline Section number & 1 & 2 & 3 & 4 & 5 & 6 & 7 & 9 \\
\hline Section diameters & $1-5$ & $5-10$ & $10-20$ & $20-30$ & $30-40$ & $40-50$ & $50-70$ & $70-90$ & $90-110$ \\
\hline Distribution 1 & 0 & 1 & 0 & 0 & 0 & 0 & 0 & 0 \\
\hline Distribution 2 & 0 & 0 & 0 & 1 & 0 & 0 & 0 & 0 \\
\hline Distribution 3 & 0 & 0 & 0 & 0 & 0 & 1 & 0 & 0 \\
\hline Distribution 4 & 0 & 0 & 0 & 0 & 0 & 0 & 0 & 1 \\
\hline
\end{tabular}

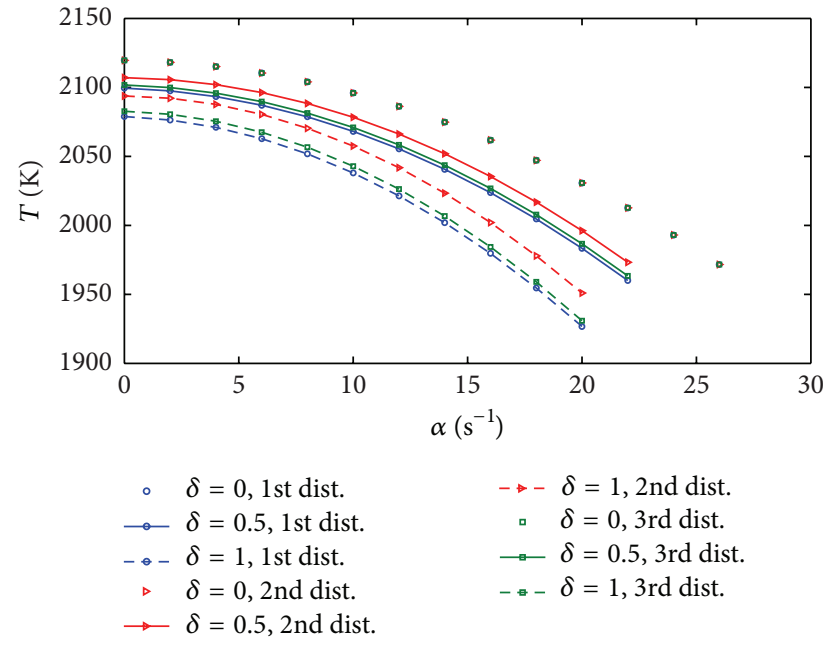

FIGURE 13: Influence of heat loss parameter on spray flame temperature for different initial droplet loads-polydisperse case.

In Figure 14 we examine the influence of the initial droplet size distributions on the ratio of the velocity at extinction to the adiabatic flame velocity. The ordering of the curves follows the pattern we have explained and impacts on the classical factor of $e^{-1 / 2}$ in accordance with that ordering and the initial droplet loading.

The impact of the initial droplet size distributions on the temperature distribution is illustrated in Figure 15. Although the profiles are similar, the differences reflect the different rates of heat loss due to droplet evaporation. As mentioned previously in connection with Figures 8, 9, and 10, initial size distribution 1 provides the most concentrated heat loss so that the associated temperature profile lies below those of the other two size distributions. Distribution 2 provides the most protracted droplet heat loss behavior thereby leading to greater temperatures than associated with the other distributions. Due to this disparity in droplet-related heat loss, differences of several tens of degrees occur at the peak temperature.

We now turn to examine more explicitly the influence of droplet size on the spray flame behavior described before. For this purpose we make use of the four initial droplet size distributions listed in Table 2.

Note that these four distributions are initially monosectional. The difference between them is the size of droplets in the fresh mixture. The SMDs for these four distributions are

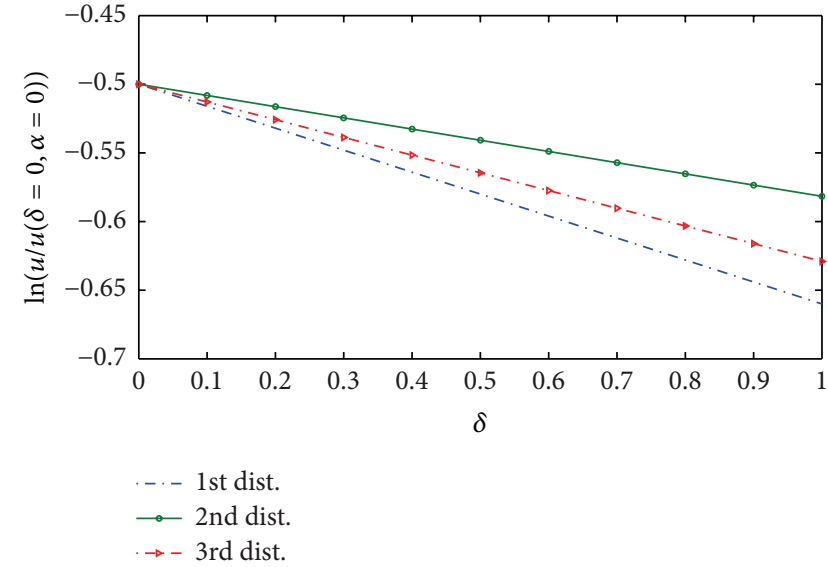

FIGURE 14: Influence of the initial droplet size distribution in determining the flame velocity of laminar spray flames as function of the initial liquid fuel load, polydisperse spray.

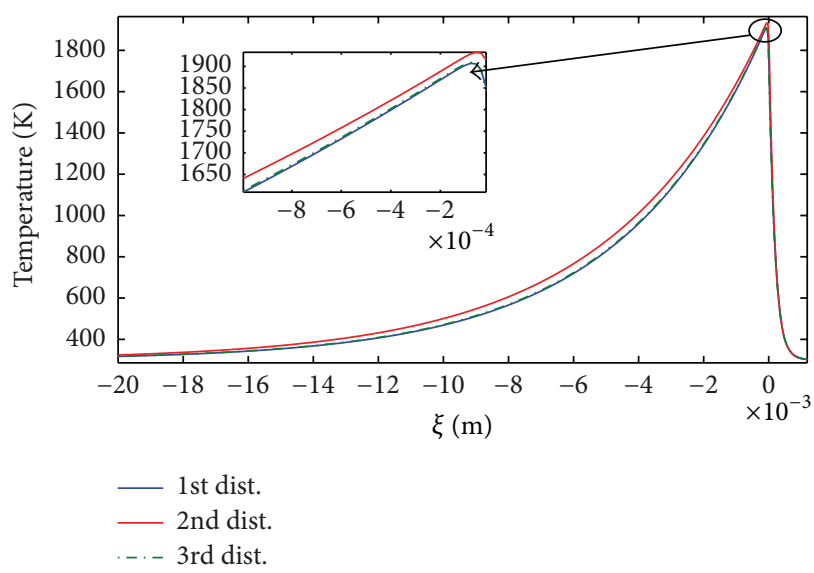

FIGURE 15: Effect of initial droplet size distribution on thermal profile in one-dimensional laminar spray flame propagation.

$7.213,24.663,44.814$, and $79.582 \mu \mathrm{m}$, respectively. The solution in (18a)-(21c) is, of course, applicable as the polydisperse development of the spray is independent of the initial size distribution.

In Figure 16 the spray flame velocity at extinction is plotted for all four cases of Table 2 as a function of the initial liquid fuel load, $\delta$. As anticipated and explained previously, 


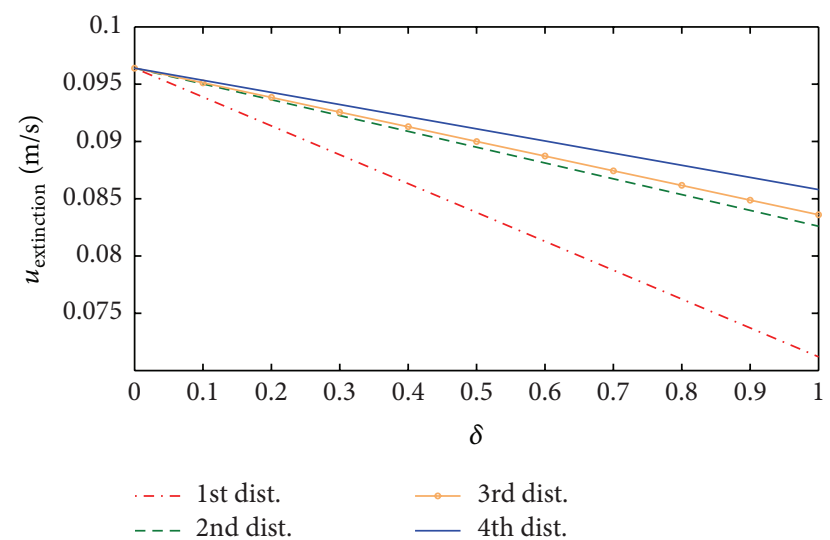

FIGURE 16: Influence of initial droplet size on extinction velocity in polydisperse spray flames.

for all four initial distributions, the critical velocity decreases as the initial liquid fuel load increases. The largest effect is noted for the case of smallest droplets for which adecrease of about $26 \%$ occurs. The initially larger droplets of distributions 2-4 of Table 2 lead to more modest maximum decreases of between $14 \%$ and $11 \%$, with the largest droplets supplying the smallest increase. This is entirely in keeping with the previous assertion that it is the way in which heat loss due to droplet evaporation is spatially distributed that determines the flame velocity. This is further confirmed by Figure 17 in which the relative importance of the volumetric and spray-related heat losses is plotted, for the initial droplet sizes of Table 2. The compound effect of both sources of heat loss is apparent. Once again it is clearly evident that the smaller the initial droplet size the more focused the droplet related heat loss, and, hence, its impact on the flame propagation velocity. The previously mentioned classical factor of $e^{-1 / 2}$ at extinction for a gas flame can become as small as $e^{-0.8}$ for size distribution 1 (of Table 2) and an initial liquid fuel load $\delta=1$.

\section{Conclusions}

The role of both volumetric/radiative heat loss and that of heat absorbed by a spray of evaporating droplets in determining premixed spray flame propagation and extinction was investigated analytically using a nonasymptotic solution of the governing equations. This is the first analytical treatment of laminar premixed polydisperse spray flame propagation with volumetric/radiation heat loss that we are aware of. Such analysis is important in terms of the physical insights it is able to supply and its potential use as a benchmark for computational studies.

Calculated results indicate that the presence of the fuel droplets in the premixture reduces both the critical value of both the flame velocity prior to extinction and the heat loss, primarily due to the aforementioned heat absorption by the droplets. In addition to the initial droplet load, the value of the evaporation coefficient and the initial size distribution are the

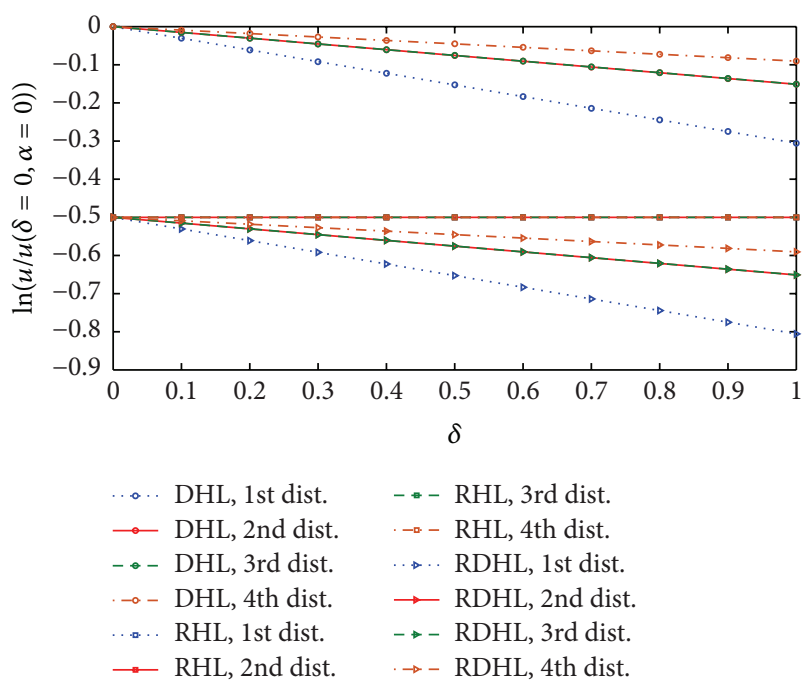

FIGURE 17: Influence of the initial droplet size in determining the flame velocity of laminar polydisperse spray flames as function of the initial liquid fuel load.

other spray-related parameters which exert an influence on the onset of extinction. The combination of these parameters governs the manner in which the spray heat loss is distributed spatially and it is this which is the main factor, when taken together with the volumetric heat loss, which determines the spray's impact on flame propagation and extinction.

In addition, the analysis demonstrates that use of a Sauter Mean Diameter to characterize the behavior of a polydisperse spray flame may lead to erroneous conclusions. In fact, the actual polydispersity of the flame must be considered.

Finally, the results clearly show how the presence of the spray and volumetric heat losses lead to a reduction of the burning velocity in comparison with a single phase gas flame, due to the total heat loss, which leads to a lowering of the burned gas temperature. It should be mentioned that, interestingly, this result does not match some experimental data for laminar premixed spray flames for which flame velocity increases were found for rich spray flames [27-29]. However, this discrepancy is due to the fact that in the current steady state, one-dimensional theory the inherently two- or three dimensional phenomenon of flame cellularization clearly cannot be captured. This necessitates a stability analysis for the two- or three dimensional perturbed flame front, which is beyond the scope of the current work.

\section{Appendix}

\section{Solution of Governing Equations When the Spray of Droplets Evaporates in a Sharp Front}

We apply a matching condition at $\xi=\xi_{v}$ that reflects the presence of vaporization front: 


$$
\begin{aligned}
& \xi=\xi_{v}: \\
& \quad\left[Y_{O}\right]=\left[Y_{O}^{\prime}\right]=0, T=T_{v},\left[T^{\prime}\right]=\frac{L m_{d u} u}{D_{T} c_{p}} .
\end{aligned}
$$

The solution can then be readily found:

$$
\begin{aligned}
\text { In } R_{1}= & \left\{\xi_{v} \leq \xi<\infty\right\}, \\
T(\xi)= & T_{0}+\left(T_{v}-T_{0}\right) \exp \left[\lambda_{2}\left(\xi-\xi_{v}\right)\right], \\
Y_{O}(\xi)= & m_{\mathrm{Ou}}\left[1+\frac{\mu_{1}}{\mu_{2}} \exp \left(-\frac{u}{D_{O}} \xi\right)\right] . \\
\text { In } R_{2}= & \left\{0 \leq \xi \leq \xi_{v}\right\} \\
T(\xi)= & T_{0}-\Lambda \exp \left[\lambda_{1}\left(\xi-\xi_{v}\right)\right] \\
& +\left[T_{v}-T_{0}+\Lambda\right] \exp \left[\lambda_{2}\left(\xi-\xi_{v}\right)\right], \\
Y_{O}(\xi)= & m_{\mathrm{O} u}\left[1+\frac{\mu_{1}}{\mu_{2}} \exp \left(-\frac{u}{D_{O}} \xi\right)\right] .
\end{aligned}
$$

$$
\text { In } R_{3}=\left\{\xi_{e} \leq \xi \leq 0\right\}
$$

$$
\begin{aligned}
& T(\xi)=T_{0} \\
& +\left[\frac{\Gamma m_{\mathrm{Ou}}\left[\lambda_{2}-\left(\mu_{1} / \mu_{2}\right) \lambda_{1}\right]}{\lambda_{2}-\lambda_{1}}-\Lambda \exp \left(-\lambda_{1} \xi_{v}\right)\right] \\
& \cdot \exp \left(\lambda_{1} \xi\right)-m_{\mathrm{Ou}}\left(1+\frac{\mu_{1}}{\mu_{2}}\right) \Gamma \exp \left(\mu_{1} \xi\right), \\
& Y_{O}(\xi)=m_{\mathrm{Ou}}\left(1+\frac{\mu_{1}}{\mu_{2}}\right) \exp \left(\mu_{1} \xi\right) . \\
& \operatorname{In} R_{4}=\left\{-\infty<\xi \leq \xi_{e}\right\} \\
& T(\xi)=T_{0}+\left(T_{*}-T_{0}\right) \exp \left[\lambda_{1}\left(\xi-\xi_{e}\right)\right], \\
& Y_{O}(\xi)=0,
\end{aligned}
$$

where

$$
\Lambda \equiv \frac{L m_{d u}}{d_{T} C_{P}} .
$$

In this vaporization front case, it can be shown that explicit expressions are obtained for $\xi_{m}, \xi_{e}, \xi_{v}$ :

$$
\begin{aligned}
& \xi_{v}=-\frac{\ln \left[\Gamma m_{\mathrm{Ou}}\left[d_{\mathrm{O}}-d_{T}\right] / d_{T}\left(1+d_{\mathrm{O}}\right)\left(T_{v}-T_{0}+\Lambda\right)\right]}{\lambda_{2}}, \\
& \xi_{e}=\frac{\ln \left\{\left(T_{*}-T_{0}\right) /\left(-\Delta_{2} \exp \left(-\lambda_{1} \xi_{v}\right)+\Gamma m_{\mathrm{Ou}}\left(d_{T}+d_{\mathrm{O}}\right) / d_{T}\left(1+d_{\mathrm{O}}\right)\right)\right\}}{\lambda_{1}}, \\
& \xi_{m}=\frac{\ln \left(\lambda_{1}\left[-\Delta_{2} \exp \left(-\lambda_{1} \xi_{v}\right)+\Gamma m_{\mathrm{Ou}}\left(d_{T}+d_{\mathrm{O}}\right) / d_{T}\left(1+d_{\mathrm{O}}\right)\right] /\left(2 \Gamma m_{\mathrm{Ou}} \mu_{1} /\left(1+d_{\mathrm{O}}\right)\right)\right)}{\mu_{1}-\lambda_{1}} .
\end{aligned}
$$

\section{Nomenclature}

$\begin{array}{ll}A: & \text { Preexponential constant } \\ B: & \text { Parameter in solution (Equation (23i)) } \\ c_{p}: & \text { Specific heat } \\ d_{l j}, d_{u j}: & \text { Lower and upper diameters of size section } \\ & j \\ d_{\mathrm{O}}, d_{T}: & \text { Parameters in solution }((23 \mathrm{e}) \text { and }(23 \mathrm{~h})) \\ D_{T}: & \text { Thermal diffusion coefficient } \\ D_{\mathrm{O}}: & \text { Oxygen mass diffusion coefficient } \\ E: & \text { Activation energy } \\ \widehat{E}_{v}: & \text { Evaporation coefficient } \\ H: & \text { Heaviside function } \\ k, K_{d}, \widehat{K}_{\mathrm{O}}: & \text { Functions defined in (8), (16), and (12), } \\ L: & \text { respectively } \\ m_{\mathrm{O} u}: & \text { Latent heat of vaporization } \\ m_{d u}: & \text { Initial mass fraction of gaseous oxygen } \\ N_{S}: & \text { Initial mass fraction of liquid fuel } \\ P: & \text { Number of size sections } \\ q: & \text { Spray-related function ((22a) and (22b)) }\end{array}$

$\begin{array}{ll}R: & \text { Universal gas constant } \\ R_{1}, R_{2}, R_{3}, R_{4}: & \begin{array}{l}\text { Solution subdomains } \\ \text { Mole fraction of oxygen in the fresh }\end{array} \\ & \text { mixture } \\ S_{v}: & \text { Total rate of droplet evaporation } \\ S_{v, j}: & \text { Rate of evaporation of droplets in section } j \\ t^{*}: & \text { Time } \\ T: & \text { Temperature } \\ T_{0}: & \text { Ambient temperature } \\ u: & \text { Velocity } \\ x^{*}: & \text { Spatial coordinate } \\ Y: & \text { Mass fraction } \\ \widehat{\alpha}, \alpha: & \text { Radiative heat loss coefficients } \\ \alpha_{\mathrm{OF}}: & \text { Stoichiometric coefficient } \\ \Gamma: & \text { Parameter in solution (Equation (23a)) } \\ \delta_{j}: & \text { Mass fraction of liquid fuel in section } j \\ \delta: & \text { Initial ratio of mass fraction of liquid fuel } \\ \delta_{j}, \Psi_{j}: & \text { to total fuel } \\ \varepsilon: & \text { Vaporization Damkohler numbers for sec- } \\ & \text { tion } j\end{array}$




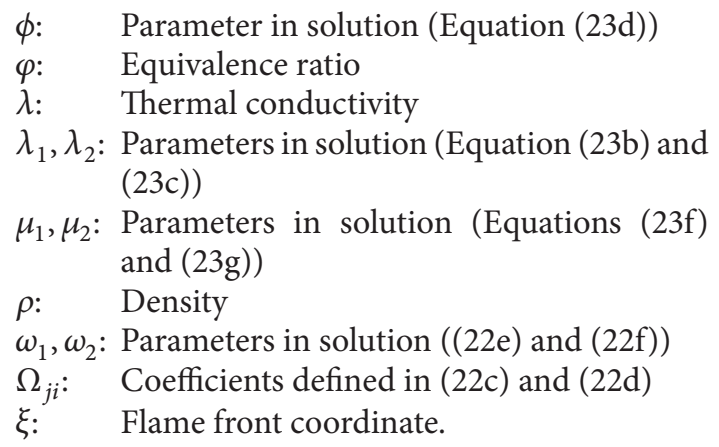

\section{Subscripts}

$\begin{array}{ll}d, j: & \text { Relating to droplets in size section } j \\ e: & \text { Reaction extinction point value } \\ j: & \text { Relating to size section } j \\ F: & \text { Fuel } \\ m: & \text { Maximum temperature point value } \\ O: & \text { Oxygen } \\ u: & \text { Unburnt value } \\ v: & \text { Vaporization front value } \\ *: & \text { Value at } \xi=0 .\end{array}$

\section{Conflict of Interests}

The authors declare that there is no conflict of interests regarding the publication of this paper.

\section{Acknowledgment}

J. B. Greenberg wishes to acknowledge the partial support of the Lady Davis Chair in Aerospace Engineering.

\section{References}

[1] D. B. Spalding, "A theory of inflammability limits and flamequenching," Proceedings of the Royal Society. Series A, vol. 240, no. 1220 , pp. 83-100, 1957.

[2] J. Adler and D. B. Spalding, "One-dimensional laminar flame propagation with an enthalpy gradient," Proceedings of the Royal Society, Series A: Mathematical, Physical and Engineering Sciences, vol. 261, no. 1304, pp. 53-78, 1961.

[3] J. Adler, "One-dimensional laminar flame propagation with distributed heat losses: thin flame theory," Combustion and Flame, vol. 7, no. 1, pp. 39-49, 1963.

[4] J. Buckmaster, "The quenching of deflagration waves," Combustion and Flame, vol. 26, no. C, pp. 151-162, 1976.

[5] G. Joulin and P. Clavin, "Linear stability analysis of nonadiabatic flames: diffusional-thermal model," Combustion and Flame, vol. 35, pp. 139-153, 1979.

[6] C. Nicoli and P. Clavin, "Effect of variable heat loss intensities in the dynamics of a premixed flame front," Combustion and Flame, vol. 68, no. 1, pp. 69-71, 1987.

[7] P. Clavin and C. Nicoli, "Effect of heat losses on the limits of stability of premixed flames propagating downwards," Combustion and Flame, vol. 60, no. 1, pp. 1-14, 1985.
[8] C.-C. Liu and T.-H. Lin, "The interaction between external and internal heat losses on the flame extinction of dilute sprays," Combustion and Flame, vol. 85, no. 3-4, pp. 468-478, 1991.

[9] S.-S. Hou, C.-C. Liu, and T.-H. Lin, "The influence of external heat transfer on flame extinction of dilute sprays," International Journal of Heat and Mass Transfer, vol. 36, no. 7, pp. 1867-1874, 1993.

[10] J. B. Greenberg, A. C. McIntosh, and J. Brindley, "Linear stability analysis of laminar premixed spray flames," Proceedings of the Royal Society of London A, vol. 457, pp. 1-31, 2001.

[11] J. B. Greenberg, "Stability boundaries of laminar premixed polydisperse spray flames," Atomization and Sprays, vol. 12, no. 1-3, pp. 123-143, 2002.

[12] C. Nicoli, P. Haldenwang, and S. Suard, "Analysis of pulsating spray flames propagating in lean two-phase mixtures with unity Lewis number," Combustion and Flame, vol. 143, no. 3, pp. 299312, 2005.

[13] C. Nicoli, P. Haldenwang, and S. Suard, "Effects of substituting fuel spray for fuel gas on flame stability in lean premixtures," Combustion and Flame, vol. 149, no. 3, pp. 295-313, 2007.

[14] W. A. Sirignano, Fluid Dynamics and Transport of Droplets and Sprays, Cambridge University Press, Cambridge, UK, 1999.

[15] S. S. Sazhin, "Advanced models of fuel droplet heating and evaporation," Progress in Energy and Combustion Science, vol. 32, no. 2, pp. 162-214, 2006.

[16] G. Kats and J. B. Greenberg, "Application of a non-asymptotic approach to prediction of the propagation of a flame through a fuel and/or oxidant droplet cloud," Applied Mathematical Modelling, vol. 37, no. 12-13, pp. 7427-7441, 2013.

[17] V. A. Volpert, "Dynamics of thermal polymerization waves," in Self-Assembly, Pattern Formation and Growth Phenomena in Nano-Sytems, A. A. Golovin and A. A. Nepomnyashchy, Eds., pp. 195-245, Springer, Amsterdam, The Netherlands, 2006.

[18] S. Balasuriya and V. A. Volpert, "Wavespeed analysis: approximating Arrhenius kinetics with step-function kinetics," Combustion Theory and Modelling, vol. 12, no. 4, pp. 643-670, 2008.

[19] J. B. Greenberg and A. Kalma, "Computational aspects of the sectional modeling method for predicting spray combustion," HTD, vol. 361, no. 2, pp. 3-10, 1998.

[20] J. B. Greenberg, I. Silverman, and Y. Tambour, "On the origins of spray sectional conservation equations," Combustion and Flame, vol. 93, no. 1-2, pp. 90-96, 1993.

[21] M. Labowsky, "Calculation of the burning rates of interacting fuel droplets," Combustion Science and Technology, vol. 22, no. 5-6, pp. 217-226, 1980.

[22] A. Bayliss, E. M. Lennon, M. C. Tanzy, and V. A. Volpert, "Solution of adiabatic and nonadiabatic combustion problems using step-function reaction models," Journal of Engineering Mathematics, vol. 79, pp. 101-124, 2013.

[23] D. R. Stull and H. Prophet, JANAF Thermochemcial Tables, NSRDS-NBS 37, National Bureau of Standards, Washington, DC, USA, 2nd edition, 1971.

[24] N. B. Vargaftik, Tables on the Thermophysical Properties of Liquids and Gases, John Wiley \& Sons, New York, NY, USA, 2nd edition, 1975.

[25] M. Zhu and B. Rogg, "Modelling and simulation of sprays in laminar flames," Meccanica, vol. 31, no. 2, pp. 177-193, 1996.

[26] V. Bykov, I. Goldfarb, V. Gol'dshtein, and J. B. Greenberg, "Auto-ignition of a polydisperse fuel spray," Proceedings of the Combustion Institute, vol. 31, no. 2, pp. 2257-2264, 2007. 
[27] Y. Mizutani and A. Nakajima, "Combustion of fuel vapor-dropair systems: part I-open burner flames," Combustion and Flame, vol. 20, no. 3, pp. 343-350, 1973.

[28] Y. Mizutani and A. Nakajima, "Combustion of fuel vapor-dropair systems: part II-spherical flames in a vessel," Combustion and Flame, vol. 20, no. 3, pp. 351-357, 1973.

[29] S. Hayashi and S. Kumagai, "Flame propagation in dropletvapor-air mixtures," Proceedings of the Combustion Institute, vol. 15, no. 1, pp. 445-452, 1974 


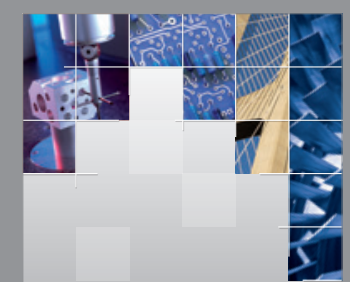

\section{Enfincering}
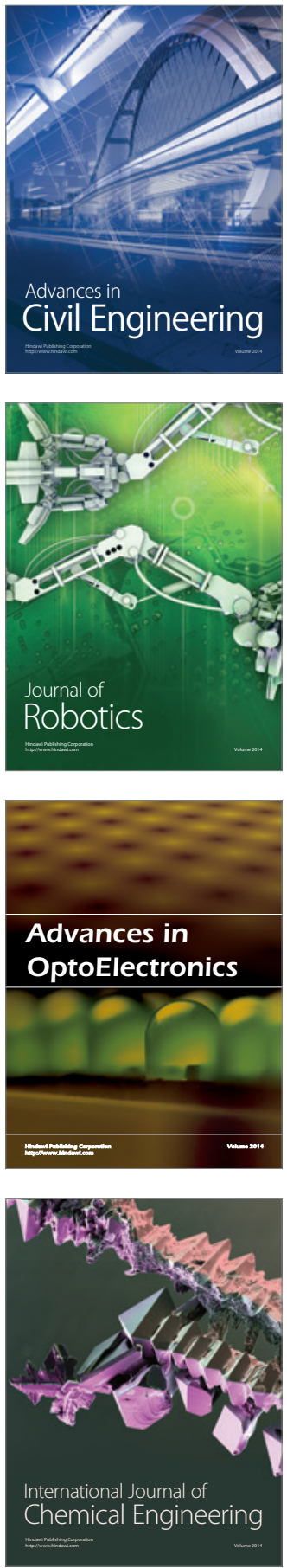

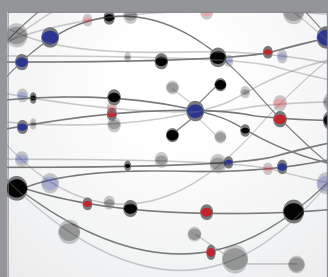

The Scientific World Journal

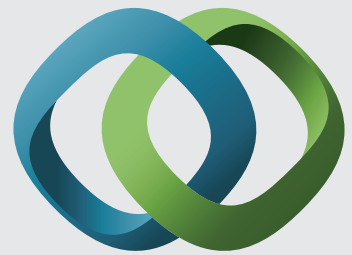

\section{Hindawi}

Submit your manuscripts at

http://www.hindawi.com
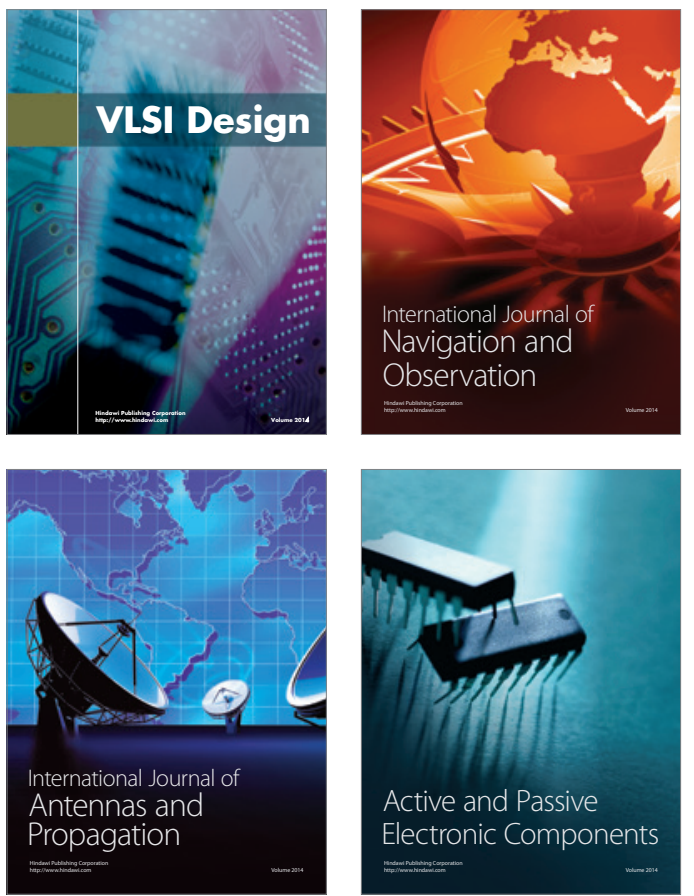
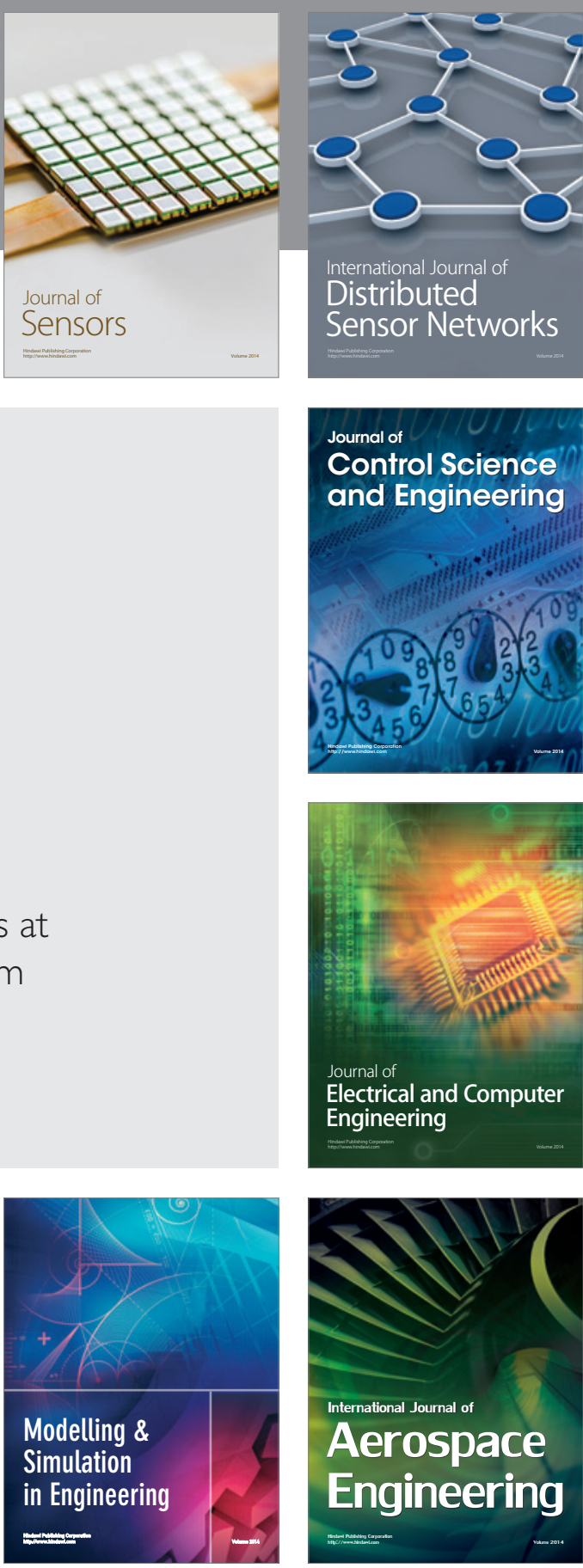

International Journal of

Distributed

Sensor Networks

Journal of

Control Science

and Engineering
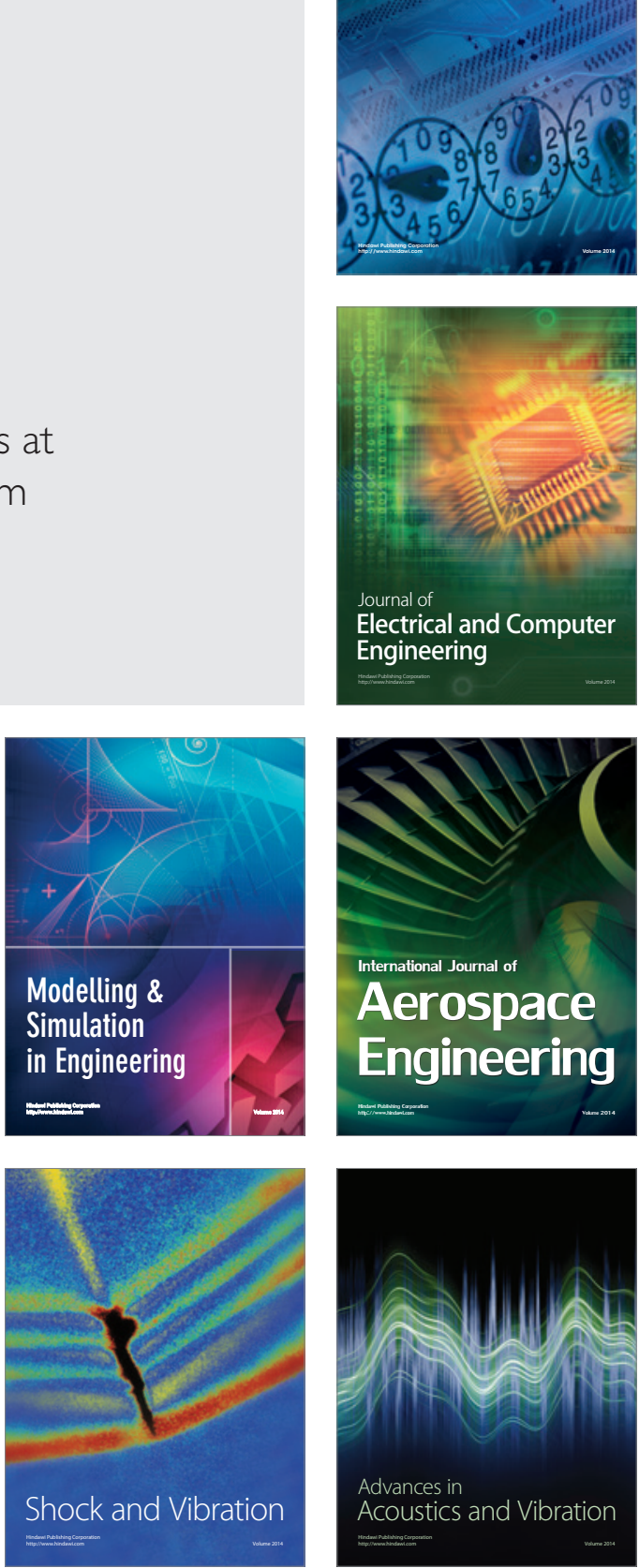